\title{
Analysis on the Factors Influencing the International Technology Transfer Based on ISM Model
}

\author{
Jing Shouwu ${ }^{1}$, Xia Yong ${ }^{1} \&$ Li Zheng $^{2}$ \\ ${ }^{1}$ Economy and Trade Insititute, The Xinjiang Agricultural University, Xinjiang, China \\ ${ }^{2}$ Shandong Linuo Solar Power Co., Ltd, China \\ Correspondence: Jing Shouwu, Economy and Trade Insititute, The Xinjiang Agricultural University, Urumqi, \\ 830052 Xinjiang, China. E-mail: jing.shouwu1988@163.com
}

Received: September 8, 2015

doi:10.5539/ijef.v8n3p206
Accepted: October 14, $2015 \quad$ Online Published: February 25, 2016

URL: http://dx.doi.org/10.5539/ijef.v8n3p206

\begin{abstract}
The technology is not only an indispensable element involved in international trade, but also an important factor affecting the comparative advantage and trade patterns in international trade. Based on predecessors' research and practice experience, this dissertation selects 20 factors to study the influencing factors, such as international technology transfer, the construction of infrastructure, the complexity of technological progress, economic development level and so on. By using the ISM model, the paper studies the correlation and gradation of influencing factors of international technology transfer. The analysis indicates there are 4 direct factors on surface and. 6 factors on path: the applicability and negotiability of the technology, international technology transfer intermediary. 3 direct factors: the construction of infrastructure. 5 indirect factors: environment changes of international economy, the complexity of technological progress. 2 factors in deep roots: economic development level and changes of industrial structure. Based on this, the paper puts forward corresponding countermeasures and suggestions from five aspects. Meanwhile, it provides certain references to improve the international technology transfer level, promote using international technology transfer to improve technology level, and upgrade the industrial structure.
\end{abstract}

Keywords: international technology transfer, influencing factors, hierarchical structure model

\section{Introduction}

\subsection{Introduce the Problem}

Stewart thought technology is a internal power. Knowledge, procedure for production, usage even any useful proposal (Du, 2012).The definition of technical transfer is that technology is transmitted from one field, sector, industry to another. While occurring in counties (areas), called international technical transfer. Viewing "international competition report published by IMD, Chinese technical overall ranking has on average and below, exactly off $20^{\text {th }}$ ( $\left.\mathrm{Li}, 2012\right)$. China has dominated worldwide international trade from 2013, so how to apply international technical transfer to lift our technical level is of particular importance.

\subsection{Explore Importance of the Problem}

The technology has been playing an important role in finalization of international trade pattern with the development of society from new classical growth theory. It is saying that technical progress is the essential element in growth model at first, according to Paul's new economic growth theory M. Romer regards technical development as endogenous power of economic growth. According to Posner theory that technology is the independent production factor. Whereas from 1980s, new-new trade theory focused on technological spillovers effects during international trade. The technical transfer has become key factor in overseas business. Technology is both essential element for involving international trade and important unit to impact overseas business comparative interest and trade pattern.

\subsection{Describe Relevant Scholarship}

There are some researches about influencing factor analysis Which is more representative of grey correlation degree, analytic hierarchy process, multi-factor and key-factor evaluation method, factor analysis, principal component analysis, fuzzy comprehensive evaluation method, Artificial neural network simulation method and 
so on and effecting factors to international technical transfer in domestic and overseas. Generally, the method to research effecting factors is to set up evaluation index system after information gathering and weight definition. While the weight decision is a little subjective and probabilistic because of different time and different area, which will affect the accuracy of empirical analysis. Some indicators are hardly measured according to existing data. The ISM model can eliminate subjectivity from valuator and avoid incomplete evaluation caused by data missing (Zhang et al., 2014). Warfield (1976) proposed the ISM system during analysis intricate society and economy, which is that graph theoretic approach and matrix transformation can change complicated social economic system to stratified one via elimination redundant parts. Amy (2010) uses ISM model to hierarchically divide technical transfer indicator from equipment suppliers and uses ANP model to appraise technical transfer effects from equipment manufacturer. Ali Diabat and Kannan Govindan (2011) uses ISM model with driving and dependent performance to divide influencing factors of green supply chain management. Bian qing (2013) divides ISM model into traditional ISM, network ISM, ISM based on driving and dependent characteristics and applies ISM with driving and dependent characteristics to study fee of nuclear station construction. There are lots of experts to research influencing factors to international technology transfer.

Wang Blomstrum (1992) come to conclusion that the degree of market competition in the host country has a positive effect ion on foreign technology ea specially on the foreign investment midnight technology. The degree of market competition shows a positive inverted U relationship with international technology transfer. Sharmila Vishwasrao has the idea that low marketing competition intensity is in favor of international technology transfer. Wang and Blomstrum (1992) thinks when the marketing competition is almost in monopolistic stage, the surge of marketing competition accelerates the technical transfer.

Teece (1977) realizes that cost of technical transfer advantage is fairly high, and it never occurs provided that switch profit is lower than transfer cost after studing 26 technical transfer projects. Lijuan Zhou (2005) insists that economic globalization is the important factor to improve international technical transfer, whereas transnational corporations is the connection link for globalization and technical transfer, the economic globalization creates and develops many globalization corporations, and transnational corporations stimulate technical development of host countries by import equipment, introduction advance technology, procurement materials. Xi Chen (2010) holds that factors of investment countries and host countries are the essential units to affect FDI technology spillover effect, infrastructure level, investment policy, human resource, industrial association, technical difference and so on are the important influenece. Zhu guilong and Li weimin (2004) analyzed that the influencing factor of international technical transfer in China considering from technology supplier, technology receiver, government, technical ability, technology transfer barrier, technology transfer channel and other aspects after research foreign-investment enterprise in pearl river delta area.Wang kun (2005) believes that constraints of international technical transfer includes technical nationality, technical protectionism, technical barrier, in-available utility of development governments etc. Yan lingfang (2007) thinks that the lower stock quantity and the quality of human capital has the negative effects to absorb technological spillovers from transnational corporation.

The results of existing research is valuable and significant to analyze effect factors of international technical transfer, improve technical process, adjustment of industrial structure of our country, while there are some deficiencies including weighting some factors, little deep excavation, lack of system and hierarchy.

\section{Method}

\subsection{Identify Subsections(ISM Model)}

Interpretative Structural Model Method which is short for ISM, raised by professor in USA back on 1973, widely used in modern systemic project by digraph, adjacent matrix and rechable matrix to hierarchial and related dealt with non sequence static system, to analyze interconnection. 


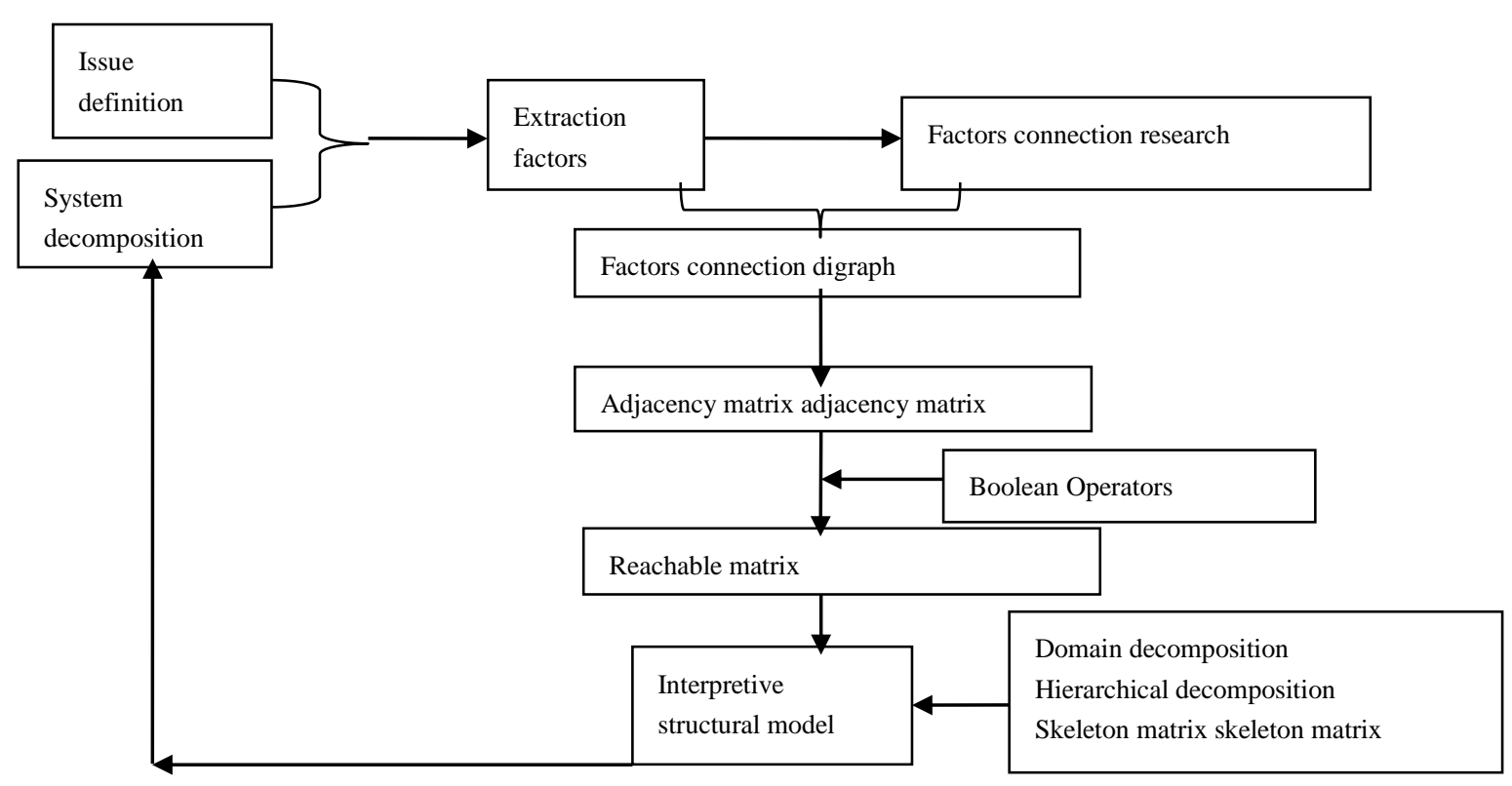

Figure 1. ISM model flow chart

\subsection{Sampling Procedures}

\subsubsection{The Selection and Relationship of Effect Factors of International Technical Transfer}

Finally choosing 20 effect factors by delphi method and review of the literatures and theories.

Table 1. The main effect factors of international technical transfer

\begin{tabular}{lll}
\hline NO. & Identification & Factors \\
\hline 1 & $\mathrm{~S}_{1}$ & The economic development level \\
2 & $\mathrm{~S}_{2}$ & International economy changes \\
3 & $\mathrm{~S}_{3}$ & Complexity of technical process \\
4 & $\mathrm{~S}_{4}$ & The willing and ability of technical supplier \\
5 & $\mathrm{~S}_{5}$ & The application and negotiability of technology \\
6 & $\mathrm{~S}_{6}$ & The ability of receive international technology \\
7 & $\mathrm{~S}_{7}$ & The changes of industrial structure \\
8 & $\mathrm{~S}_{8}$ & International technical transfer intermediary \\
9 & $\mathrm{~S}_{9}$ & Transnational corporation \\
10 & $\mathrm{~S}_{10}$ & International technical transfer type \\
11 & $\mathrm{~S}_{11}$ & Government strategy and policy \\
12 & $\mathrm{~S}_{12}$ & Laws and acts \\
13 & $\mathrm{~S}_{13}$ & Human resources \\
14 & $\mathrm{~S}_{14}$ & The incomplete of market and uncertainty of information \\
15 & $\mathrm{~S}_{15}$ & Infrastructural \\
16 & $\mathrm{~S}_{16}$ & Technical gap \\
17 & $\mathrm{~S}_{17}$ & economic openness \\
18 & $\mathrm{~S}_{18}$ & Marketing competition \\
19 & $\mathrm{~S}_{19}$ & Technology lifecycle \\
20 & $\mathrm{~S}_{20}$ & Cultural tradition \\
\hline & &
\end{tabular}

The above 20 effect factors are research objectives.

$a_{i j}\left\{\begin{array}{l}1, i \neq j, S_{1} \text { has a direct effect on } S_{1} . \\ 0, i \neq j, S_{1} \text { does not have direct effect; or } i=j \text { (Tang et al., 2007). The relationship of } s_{1} \text { can be seen on Table } 2 .\end{array}\right.$ 
Table 2. Relationships of factors effecting international technical transfer

\begin{tabular}{lllllllllllllllllllll}
\hline & $\mathrm{S}_{1}$ & $\mathrm{~S}_{2}$ & $\mathrm{~S}_{3}$ & $\mathrm{~S}_{4}$ & $\mathrm{~S}_{5}$ & $\mathrm{~S}_{6}$ & $\mathrm{~S}_{7}$ & $\mathrm{~S}_{8}$ & $\mathrm{~S}_{9}$ & $\mathrm{~S}_{10}$ & $\mathrm{~S}_{11}$ & $\mathrm{~S}_{12}$ & $\mathrm{~S}_{13}$ & $\mathrm{~S}_{14}$ & $\mathrm{~S}_{15}$ & $\mathrm{~S}_{16}$ & $\mathrm{~S}_{17}$ & $\mathrm{~S}_{18}$ & $\mathrm{~S}_{19}$ & $\mathrm{~S}_{20}$ \\
\hline $\mathrm{S}_{1}$ & 0 & 0 & 0 & 0 & 0 & 1 & 1 & 0 & 0 & 0 & 0 & 0 & 1 & 1 & 1 & 0 & 0 & 0 & 0 & 0 \\
$\mathrm{~S}_{2}$ & 0 & 0 & 0 & 0 & 0 & 0 & 0 & 0 & 1 & 0 & 0 & 0 & 0 & 0 & 0 & 0 & 1 & 0 & 0 & 0 \\
$\mathrm{~S}_{3}$ & 0 & 0 & 0 & 1 & 1 & 0 & 0 & 0 & 0 & 1 & 0 & 0 & 0 & 0 & 0 & 1 & 0 & 0 & 0 & 0 \\
$\mathrm{~S}_{4}$ & 0 & 0 & 0 & 0 & 0 & 0 & 0 & 0 & 0 & 1 & 0 & 0 & 0 & 0 & 0 & 0 & 0 & 0 & 0 & 0 \\
$\mathrm{~S}_{5}$ & 0 & 0 & 0 & 1 & 0 & 0 & 0 & 0 & 0 & 0 & 0 & 0 & 0 & 0 & 0 & 0 & 0 & 0 & 0 & 0 \\
$\mathrm{~S}_{6}$ & 0 & 0 & 0 & 0 & 0 & 0 & 0 & 0 & 0 & 1 & 1 & 0 & 0 & 0 & 0 & 0 & 0 & 0 & 0 & 0 \\
$\mathrm{~S}_{7}$ & 0 & 0 & 0 & 0 & 0 & 0 & 0 & 0 & 0 & 0 & 0 & 0 & 0 & 0 & 0 & 0 & 0 & 0 & 1 & 0 \\
$\mathrm{~S}_{8}$ & 0 & 0 & 0 & 1 & 0 & 0 & 0 & 0 & 0 & 0 & 0 & 0 & 0 & 0 & 0 & 0 & 0 & 0 & 0 & 0 \\
$\mathrm{~S}_{9}$ & 0 & 0 & 0 & 1 & 0 & 0 & 0 & 0 & 0 & 1 & 0 & 0 & 0 & 0 & 0 & 0 & 0 & 0 & 0 & 0 \\
$\mathrm{~S}_{10}$ & 0 & 0 & 0 & 0 & 0 & 0 & 0 & 0 & 0 & 0 & 0 & 0 & 0 & 0 & 0 & 0 & 0 & 0 & 0 & 0 \\
$\mathrm{~S}_{11}$ & 0 & 0 & 0 & 0 & 0 & 0 & 0 & 0 & 0 & 1 & 0 & 0 & 0 & 0 & 0 & 0 & 0 & 0 & 0 & 0 \\
$\mathrm{~S}_{12}$ & 0 & 0 & 0 & 0 & 0 & 0 & 0 & 0 & 0 & 0 & 1 & 0 & 0 & 0 & 0 & 0 & 0 & 0 & 0 & 0 \\
$\mathrm{~S}_{13}$ & 0 & 0 & 0 & 0 & 0 & 0 & 0 & 0 & 0 & 0 & 0 & 0 & 0 & 0 & 0 & 0 & 0 & 0 & 0 & 0 \\
$\mathrm{~S}_{14}$ & 0 & 0 & 0 & 0 & 0 & 0 & 0 & 0 & 0 & 1 & 0 & 0 & 0 & 0 & 0 & 0 & 0 & 0 & 0 & 0 \\
$\mathrm{~S}_{15}$ & 0 & 0 & 0 & 0 & 0 & 1 & 0 & 0 & 0 & 0 & 0 & 0 & 0 & 0 & 0 & 0 & 0 & 0 & 0 & 0 \\
$\mathrm{~S}_{16}$ & 0 & 0 & 0 & 0 & 1 & 1 & 0 & 0 & 0 & 0 & 0 & 0 & 0 & 0 & 0 & 0 & 0 & 0 & 0 & 0 \\
$\mathrm{~S}_{17}$ & 0 & 0 & 0 & 0 & 0 & 0 & 0 & 0 & 1 & 0 & 0 & 0 & 0 & 1 & 0 & 0 & 0 & 1 & 0 & 0 \\
$\mathrm{~S}_{18}$ & 0 & 0 & 0 & & 0 & 0 & 0 & 0 & 0 & 0 & 0 & 0 & 0 & 1 & 0 & 0 & 0 & 0 & 0 & 0 \\
$\mathrm{~S}_{19}$ & 0 & 0 & 1 & 1 & 1 & 0 & 0 & 0 & 0 & 1 & 0 & 0 & 0 & 0 & 0 & 0 & 0 & 0 & 0 & 0 \\
$\mathrm{~S}_{20}$ & 0 & 0 & 0 & 0 & 0 & 0 & 0 & 0 & 0 & 0 & 0 & 0 & 1 & 0 & 0 & 0 & 0 & 0 & 0 & 0 \\
\hline
\end{tabular}

\subsubsection{Build up the Rechable Matrix}

Computing adjacency matrix (A) and unit matrix Based on Boolean operation method. $(0+0=0,0+1=1,1+1=1$, $1 * 0=0,0 * 1=0,1 * 1=1)$ to $(A+I)^{K-1} \neq(A+I)^{K}=(A+I)^{K}=M, M$ is rechable matrix.

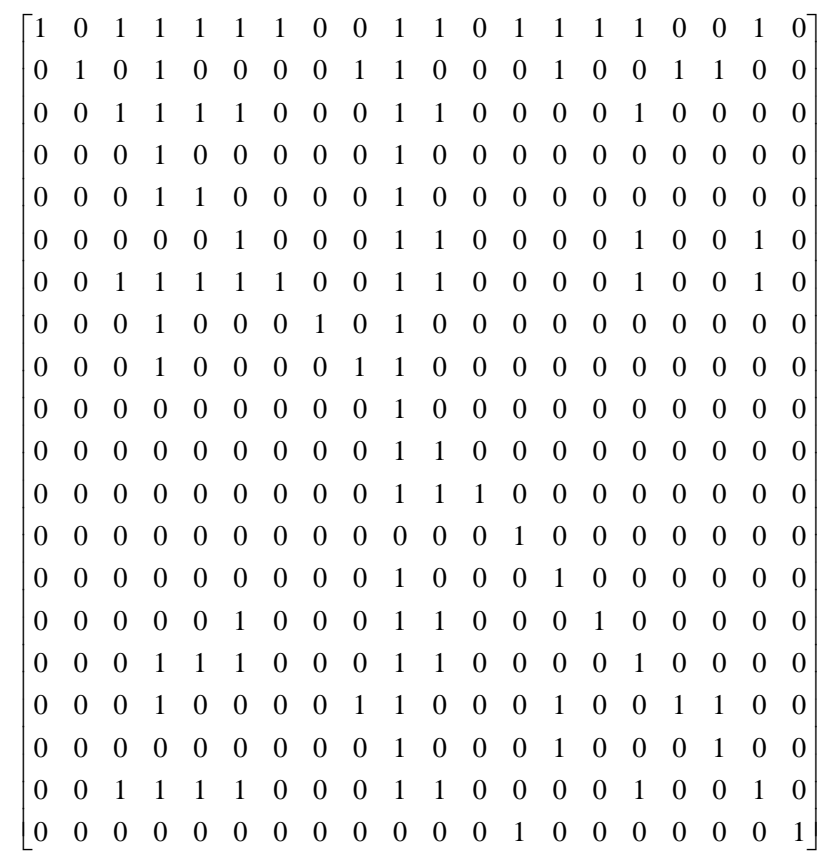

\subsubsection{Domain Decomposition of Rechable Matrix}

Rechable set, antecedent set and intersection set can domain decomposition to rechable matrix.

$\mathrm{R}\left(\mathrm{S}_{\mathrm{i}}\right)$ is Rechable set; $\mathrm{Q}\left(\mathrm{S}_{\mathrm{i}}\right)$ is antecedent set; $\mathrm{H}=\mathrm{R}\left(\mathrm{S}_{\mathrm{i}}\right) \cap \mathrm{Q}\left(\mathrm{S}_{\mathrm{i}}\right)$ is intersection set 
Table 3. Rechable set, antecedent set and intersection set

\begin{tabular}{llll}
\hline $\mathrm{i}$ & $\mathrm{R}(\mathrm{Si})$ & $\mathrm{Q}(\mathrm{Si})$ & $\mathrm{R}(\mathrm{Si}) \cap \mathrm{Q}(\mathrm{Si})$ \\
\hline 1 & $1,3,4,5,6,7,10,11,13,14,15,16,19$ & 1 & 1 \\
2 & $2,4,9,10,14,17,18$ & 2 & 2 \\
3 & $3,4,5,6,10,11,16$ & $1,3,7,19$ & 3 \\
4 & 4,10 & $1,2,3,4,5,7,8,9,16,17,19$ & 4 \\
5 & $4,5,10$ & $1,3,5,7,16,19$ & 5 \\
6 & $6,10,11$ & $1,3,6,7,15,16,19$ & 6 \\
7 & $3,4,5,6,7,10,11,16,19$ & 1,7 & 7 \\
8 & $4,8,10$ & 8 & 8 \\
9 & $4,9,10$ & $2,9,17$ & 9 \\
10 & 10 & $1,2,3,4,5,6,7,8,9,10,11,12,14,15,16,17,18,19$ & 10 \\
11 & 10,11 & $1,3,6,7,11,12,15,16,19$ & 11 \\
12 & $10,11,12$ & 12 & 12 \\
13 & 13 & $1,13,20$ & 13 \\
14 & 10,14 & $1,2,14,17,18$ & 14 \\
15 & $6,10,11,15$ & 1,15 & 15 \\
16 & $4,5,6,10,11,16$ & $1,3,7,16,19$ & 16 \\
17 & $4,9,10,14,17,18$ & 2,17 & 17 \\
18 & $10,14,18$ & $2,17,18$ & 18 \\
19 & $3,4,5,6,10,11,16,19$ & $1,7,19$ & 19 \\
20 & 13,20 & 20 & 20 \\
\hline
\end{tabular}

\section{The Hierarchical Structure of International Technology Transfer Factor}

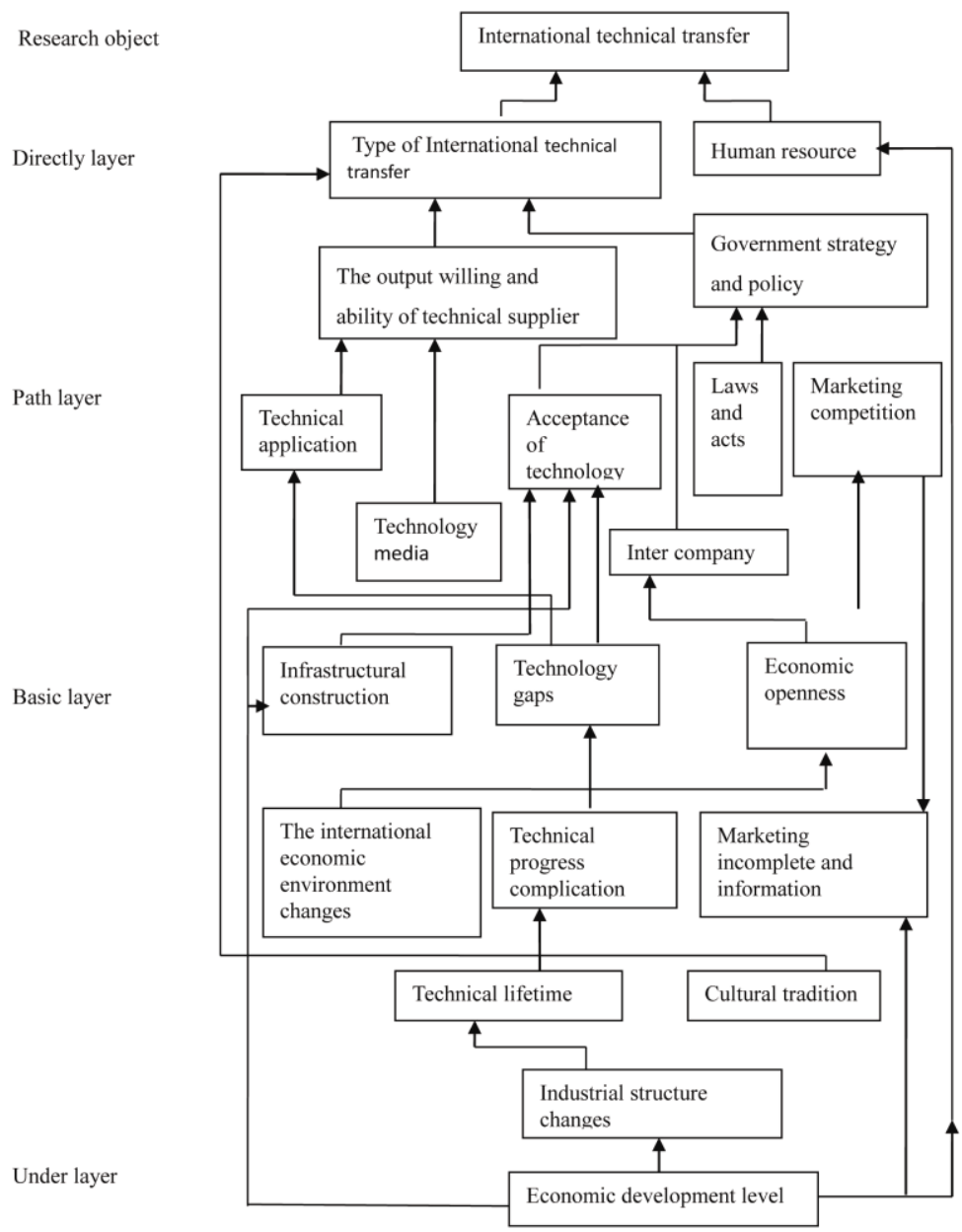

Figure 2. The hierarchical structure of international technology transfer factor 


\section{Discussion}

Technical transfer type, human resources, the output willing and ability of technical supplier and government strategy and policy are directly layer factors from diagram 2. Technical application and negotiability, technical transfer intermediary, acceptance ability of international technology, international companies, laws and acts, the level of marketing competition are acting path layer. Infrastructure construction, technical gap, economic openness, international economic environment change, technological progress complexity, the uncertainty of market incompleteness, technology life cycle and cultural tradition are basic layer; Infrastructure construction, technical gap, economic openness are direct action layer, international economic environment change, technological progress complexity, the uncertainty of market incompleteness, technology life cycle and cultural tradition are indirect action layer. The economic development level and the changes of industrial structure are deep factors, while the economic development level is the most key factor.

\subsection{Surface Direct Influenced Factors}

Technical transfer type, human resources, the output willing and ability of technical supplier and government strategy and policy are surface layer direct factors. Back on 1960's, Schultz and Becker put forward human resource theory. Higher of human capital level, better to digest absorb and re-innovate of technology. Only technical advantages from technology supplier compared with technology acceptor and the technical transfer profits are higher than transfer cost, realized technical transfer is. Govern strategy and policy will affect technical transfer appearance, technical transfer field and regional selection. So govern strategy and policy and the output willing and ability of technical supplier will affect international transfer type. The correct selection of international technical transfer type and the improvement of our human capital quantities and quality will decide the technical transfer results.

\subsection{Effect Factors of Action Layer}

Technical application and negotiability, technical transfer intermediary, acceptance ability of international technology, international companies, laws and acts, the level of marketing competition are acting path layer. Technical application and negotiability must apply with our real condition. The low level technical and high energy consumption technology can not fit our development. The more complete of international technical transfer medium, higher level of market, that will be good for the technical transfer come-up. Our acceptance technical ability is direct proportion with technical transfer affect. With complete laws and actions, improving intellectual property protection, the technical transfer and spillover is more obvious. The marketing competition is active force to international technical transfer. More serious competition, faster speed of international transfer, more willing supplier will take the marketing action to transfer the international technology.

More complete laws and actions, higher connection with the world, and more serious competition, the international companies will tend to take the commercial action to transfer the technology.

\subsection{The Effect Factors of Basic Base}

Infrastructure construction, technical gap, economic openness, international economic environment change, technological progress complexity, the uncertainty of market incompleteness, technology life cycle and cultural tradition are basic layer; Infrastructure construction, technical gap, economic openness are direct action layer, international economic environment change, technological progress complexity, the uncertainty of market incompleteness, technology life cycle and cultural tradition are indirect action layer. Infrastructure construction can effect the technical transfer speed and technical innovation popularizing rate. Technical transfer is systemic. The technical transfer scale and construct should apply technical gap between technical supplier and technical acceptor.The technical gap between technical supplier and technical acceptor can effect technical transfer cost, further affect technical transfer effects. Better economic openness, international trade, FDI, international cooperation, easier international technical transfer. The globalization and regional election system will affect international technical transfer progress. Complexity of technical progress will block whole technology transfer and weaken technical transfer.

\subsection{The Basic Effective Factors}

The factors of economic development and industrial structure belong to deep root ones, while the level of economic development is the most basic reason.

\section{Research Conclusion and Policy Enlightenment}

Generally, international technical transfer, definitely transnational technical transfer will be affected by global economic environment. 
Secondly, international technical transfer is the commercial marketing action, which will be effected by our marketing factors. It is mainly shown by our marketing competitiveness. Moreover, technical transfer will be turned into enterprise economy action finally, which will be influenced by acceptance technical ability, human resources in micro layer. Marketing environment factors mainly effect technical transfer's objective willing (Hu, 2004).

Using ISM Model, by statistics analysis, which has a very good agreement with the experimental data, we got international technical transfer effects and its' incidence relation and layer instruction.

The results prove that international technical transfer method, human resource, the willing of technical supplier, the government strategy and policy, those are surface direct factors; the technical applicability and negotiability, international technical transfer medium, receptivity of international technology, transnational company, laws and actions, marketing competition degree are acting layer. Infrastructure construction, technical gap, economic openness, international economic environment change, technological progress complexity, the uncertainty of market incompleteness, technology life cycle and cultural tradition are base layer; Infrastructure construction, technical gap, economic openness are direct action layer, international economic environment change, technological progress complexity, the uncertainty of market incompleteness, technology life cycle and cultural tradition are indirect action layer. Economic development level and the change of industrial structure are deep level, while economic development level is the deepest factor.

We can get the policy suggestion and enlightenment based on the above research: (1) Improve our economic development quality, the innovation intension to shorten the technical gap with developed countries, promote industrial internal adjustment and upgrade. (2) Active involvement global economic integration to promote economic openness and socialist market economy. (3) Government should make the reasonable adjustment to developing and investment strategy, intensify high-tech products export and direct investment, attract excellent investment, investment orientation slant to mid-west area to promote local technical level. (4) Specially, human capital should be fostered, reinforcing the scientific research and force "going-out" strategy work with transnational corporation.

\section{References}

Aditya, M., Marcelo, O., \& Kamal, S. (2004). mode of Foreign Entry, Technology Transfer and FDI Policy. Journal of Development Economics, 75(1), 96-109.

Ali, D. (2011). Kannan Govindan. An analysis of the drivers affecting the implementation of green supply chain management? Resources, Conservation and Recycling, 2011(55), 659-667.

Amy, H. I. L., Wei-Ming, W., \& Tsai-Ying, L. (2010). An evaluation framework for technology transfer of new equipment in high technology industry. Technological Forecasting \& Social Change, 2010(77), 135-1500.

Armila, V., \& William, B. (2001). Foreign ownership technology adoption. Journal of Development Economics, 65(2), 370-385.

Bian, Q. (2013). Research on Cost Control of Nuclear Power Construction Project Based on ISM-Fuzzy AHP (pp. 3-6). Bei jing: North China Electric Power University.

Chen, X. (2010). Analysis of FDI Technology Spillover Effect and the Influence Factors (Vol. 6, pp. 23-31). Qingdao: Ocean University of China.

Guilong, Z., \& Weimin, L. (2004). Analysis on the Factors Influencing the of International Technology to China's Technology Transfer. Science of Science and Management of S.\&T., 2004(6), 31-35.

Hu, J. (2004). Analysis of the Factors Affect $\mathrm{MVC}_{\mathrm{s}}$ 'Technology Transfer. East China Economic Management, 2004(6), 110-113.

Jian Y. W., \& Magnus, B. (1992). Foreign Investment and Technology Transfer. European Economic Review, 1992(11), 188-207.

Li, J. (2012). International Business and Economic Growth. China Social Sciences Press, 2012(11), 2-3.

Lijuan, Z. (2005). Interactive mechanism for international technology transfer and economic globalization. Sciende-Technology and Management, 2005(3), 100-101.

Lingfang, Y. (2007). Research on the Relationship between $M N C_{s}^{\prime}$ Technology Transfer and China's Technological Progresses (pp. 16-18). Changsha: Hunan University.

Qihua, D. (2012). International Technology Transfer. University of International Business and Economics Press, (11), 2-3. 
Shimin, S., Feng, Y., \& Haifeng, Z. (2014). Analysis on the Factors Influencing the Mutton Price Based on ISM. Journal of Agrotechnical, 2014(8), 53-59.

Teece. (n. d.). Multinational Corporation and Resource Cost of International Technology Transfer. Ballinger ,Cambridge.

Wang, K. (2005). International technology transfer mechanism under the condition of economic globalization (pp. 57-63). Quan zhou: Huaqiao University.

Warfield, J. N. (1976). Societal Systems: Planning, Policy and Complexity (pp. 12-20). New York: John Wiley \& Sons.

Yang, Z., Linxiu, W., \& Fanbo, X. (2014). The Analysis of High-tech Industrial Development Zone Investment Environment on the Basis of ISM -Taking Xuzhou High-tech Industrial Development Zone as a Case. Science and Technology Management Research, 2014(3), 127-130.

Yanli, T., Qiuyan, Z., \& Huiqin, W. (2007). Research on Risk of Software Industry Carrying on International Industry Transfer Based on ISM. Value Engineering, 2007(8), 1-4.

\section{Copyrights}

Copyright for this article is retained by the author(s), with first publication rights granted to the journal.

This is an open-access article distributed under the terms and conditions of the Creative Commons Attribution license (http://creativecommons.org/licenses/by/3.0/). 